\title{
Mercury content in the hair of residents of Babushkinsky district, Vologda region, Russia
}

\author{
Olga Rumiantseva ${ }^{1 *}$,Elena Ivanova ${ }^{1}$, Nadezhda Poddubnaya ${ }^{1}$ and Ulyana Protasevich $^{2}$ \\ ${ }^{1}$ Ecological-research laboratory, Department of biology, Cherepovets State University, 162600, \\ Cherepovets, Russia \\ ${ }^{2}$ Laboratory of applied toxicology and safety of medical devices, Scientific and Practical Center of \\ Hygiene, 220012, Minsk, Belarus
}

\begin{abstract}
Mercury is a highly toxic metal for all living organisms. Even low doses of the organic form of mercury can cause disruption in some functions of the human body. The content of mercury in the hair of residents $(\mathrm{n}=71)$ of Babushkinsky district, Vologda region, Russia was determined. Babushkinsky district is located away from industrial sources of mercury. Mercury concentrations were determined using a mercury analyzer RA-915M. The average mercury content in the hair of residents of Babushkinsky district, Vologda region was $0.398 \mathrm{mg} / \mathrm{kg}$. $8 \%$ of the study participants had mercury levels in their hair above $1 \mathrm{mg} / \mathrm{kg}$. There were no differences in the content of mercury in the hair between males $(0.540$ $\mathrm{mg} / \mathrm{kg})$ and females $(0.344 \mathrm{mg} / \mathrm{kg})$. The differences were established depending on age: under 30 years old $(0.208 \mathrm{mg} / \mathrm{kg})$, over 30 years $(0.582$ $\mathrm{mg} / \mathrm{kg}$ ). There is also a correlation between mercury in the hair and age. People who eat fish several times a week have twice as much mercury $(0.538 \mathrm{mg} / \mathrm{kg})$ as people who eat fish less than once a month $(0.262$ $\mathrm{mg} / \mathrm{kg}$ ).
\end{abstract}

\section{Introduction}

Mercury is a highly toxic metal for all living organisms. Sources of mercury are both natural and anthropogenic factors [1]. Mercury in nature exists in different forms, getting into the reservoir, it is converted from an inorganic to a more toxic organic formmethylmercury. In the eastern districts of the Vologda Region, the highest indicator of the density of the river network was recorded: more than $1 \mathrm{~km} / \mathrm{km} 2$ in the Babushkinsky district. At the same time, the Babushkinsky district has the lowest percentage of wetlands (less than 5\%). Methylmercury can be transmitted through the food chain and the maximum concentrations are observed in the muscles of predatory fish [2]. The determination of mercury in hair is widely used in assessing the level of ingestion of this metal in the human body [1]. The levels of mercury in the hair are directly correlated with the levels of mercury in the blood [3]. The negative effects of mercury on the human body have been extensively studied. Even low doses of the organic form of mercury can cause a violation of brain function, with the probability of occurrence of neuropsychological disorders in the areas of

* Corresponding author: oiumaksimova@,chsu.ru 
speech, attention and memory, and motor functions [4]. The US Environmental Protection Agency (US EPA) has established recommended levels of mercury in hair $(<1 \mathrm{mg} / \mathrm{kg})$, which correspond to the reference intake dose (RFD) of $0.1 \mathrm{mkg} / \mathrm{kg}$ of body weight per day [5]. The accumulation of mercury in biotic and abiotic components of biosystems has been studied in the Vologda region for the last decades [6-8]. On the territory of the Vologda region, the content of mercury in hair was studied only in one coastal Kirillovsky district and the industrial city of Cherepovets $[9,10]$.

The purpose of this work is to assess the factors that affect the accumulation of mercury in the hair of residents of a remote industrial source of pollution.

\section{Materials and methods}

In the period from 2017-2018, 71 hair samples of residents of Babushkinsky district, Vologda region were analyzed $\left(59.66^{\circ} \mathrm{N}\right.$ and $\left.43.85^{\circ} \mathrm{E}\right)$ (Fig.1).

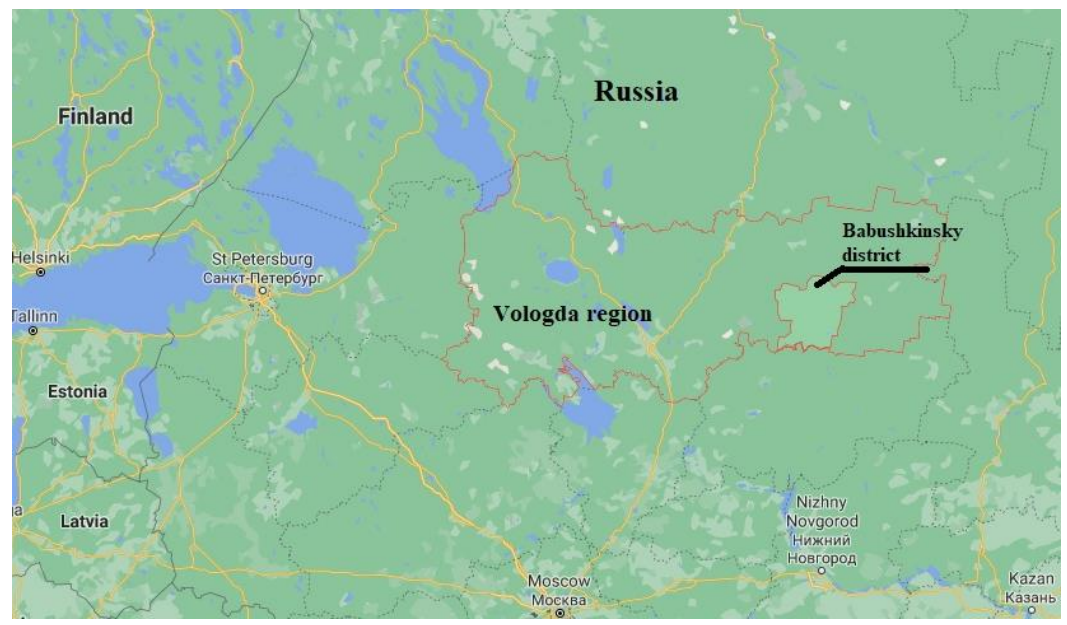

Fig. 1. The region of research

The samples were collected according to the recommendations of the World Health Organization (WHO). Each person signed a written agreement to participate in the study. This study was completed in accordance with the World Medical Association (WMA) Declaration of Helsinki: ethical principles for medical research involving human subjects. Also, the study participants filled out a questionnaire in which they indicated their gender, age, and frequency of consumption of fish products. At the same time, such parameters as the quality of drinking water, cosmetic products, and housing conditions were not taken into account in the study. The mercury content was determined by the atomic absorption method on a mercury analyzer RA-915M. To analyze the hair on the device, a piece of hair ( 2 centimeters from the roots) was taken. To check the accuracy of the device, the mercury content in reference samples (DORM-4, DOT-5) with a known mercury concentration $(\mathrm{mg} / \mathrm{kg})$ was determined.

It was found that this sample was distributed abnormally, according to the ShapiroWilk test and Kolmogorov-Smirnov Test. Consequently, nonparametric methods were used to establish statistically significant differences: the Mann-Whitney U-Test and the KruskalWallis test, with a significance level (p) less than 0.05 . To establish the correlation dependencies, Spearman's rank correlation coefficient was used at $p \leq 0.05$. The data is presented in the form of an arithmetic mean, median, standard deviation, and average error. In the text, the data is presented as a mean $\pm(\mathrm{SE})$. 


\section{Results and discussion}

The average content of mercury in the hair of residents of the Babushkinsky district is $0.398=0.053 \mathrm{mg} / \mathrm{kg}$, varies from 0.001 to $2.830 \mathrm{mg} / \mathrm{kg}$ (Table 1 ).

Table 1. Descriptive statistics of mercury concentrations in hair of residents of Babushkinsky district, $\mathrm{mg} / \mathrm{kg}$.

\begin{tabular}{|c|c|c|c|c|c|c|}
\hline $\mathrm{N}$ & Mean & Median & Minimum & Maximum & SD & SE \\
\hline 71 & 0.398 & 0.306 & 0.001 & 2.830 & 0.444 & 0.053 \\
\hline
\end{tabular}

The values of mercury in the population of Babushkinsky district are significantly lower than the values of the coastal territories of Kirillovsky district $(1.139 \mathrm{mg} / \mathrm{kg})$, Brazil $(16.400 \mathrm{mg} / \mathrm{kg})$, and the gold mining region Kadoma/Zimbabwe $-1.47 \mathrm{mg} / \mathrm{kg}[9,11,12]$. The results of the current study are more than twice as high as the levels of mercury in the hair of residents of the industrial city of the Vologda region Cherepovets $(0.194 \mathrm{mg} / \mathrm{kg})$, central Poland $(0.174 \mathrm{mg} / \mathrm{kg})$, and Germany $(0.109 \mathrm{mg} / \mathrm{kg})[10,14]$.

In this study, $8 \%$ (6 people) of all the people studied had an excess of $1 \mathrm{mg} / \mathrm{kg} .6 \%$ of the population in Naples, Italy has mercury levels in hair exceeding the levels of $1 \mathrm{mg} \mathrm{Hg} / \mathrm{kg}$ hair [15].

Mercury concentrations in hair do not differ significantly between males and females (Table 2). The average mercury value for males of the Babushkinsky district is $0.540 \pm$ $0.147 \mathrm{mg} / \mathrm{kg}$, while for females, it is $0.344 \pm 0.041 \mathrm{mg} / \mathrm{kg}$.

No differences in mercury content between men and women were found in residents of the coastal Kirillovsky district, Russia (males $-0.94 \mathrm{mg} / \mathrm{kg}$, females $-0.72 \mathrm{mg} / \mathrm{kg}$ ) and residents of the Russian city of Cherepovets (males - $0.174 \mathrm{mg} / \mathrm{kg}$, females - 0.201 $\mathrm{mg} / \mathrm{kg})[9,10]$. Also, gender differences were not found in the study on the territory of Upper Maroni, French Guiana (males $-9.4 \mathrm{mg} / \mathrm{kg}$, females $-9.9 \mathrm{mg} / \mathrm{kg}$ ) [16]. At the same time, differences in the level of mercury in hair were noted by sex in the adult population of the Karakuwacho Peninsula, Japan [17].

Table 2. Indicators of mercury content in hair of male and female of Babushkinsky district, $\mathrm{mg} / \mathrm{kg}$

\begin{tabular}{|c|c|c|c|c|c|c|c|}
\hline Gender & $\mathrm{N}$ & Mean & Median & Minimum & Maximum & SD & SE \\
\hline Female & 49 & 0.344 & 0.306 & 0.001 & 1.104 & 0.290 & 0.041 \\
\hline Male & 21 & 0.540 & 0.339 & 0.010 & 2.830 & 0.674 & 0.147 \\
\hline
\end{tabular}

All the people who took part in the study were divided into 2 age groups: the first under 30 years; the second - over 30 years. The mercury content in people under 30 years of age is significantly lower $(0.208=0.038 \mathrm{mg} / \mathrm{kg})$ than in people over 30 years of age $(0.582=0.087 \mathrm{mg} / \mathrm{kg}), p=0.001$ (Table.3).

Table 3. The indicators of mercury content in human hair of different age groups, $\mathrm{mg} / \mathrm{kg}$

\begin{tabular}{|c|c|c|c|c|c|c|c|}
\hline Age group & $\mathrm{N}$ & Mean & Median & Minimum & Maximum & SD & SE \\
\hline under 30 years & 35 & 0.208 & 0.153 & 0.001 & 1.154 & 0.226 & 0.038 \\
\hline over 30 years & 36 & 0.582 & 0.474 & 0.010 & 2.830 & 0.523 & 0.087 \\
\hline
\end{tabular}

Earlier studies of coastal cities in China and the Kirillovsky district in Russia, as well as the industrial city of Cherepovets, Russia, also showed an increase in mercury concentrations in hair with age $[9,10]$.

According to the content of mercury in the hair of residents of the Babushkinsky district from age, the correlation dependence $r s=0.458(p=0.000)$ was established (Fig.2). 


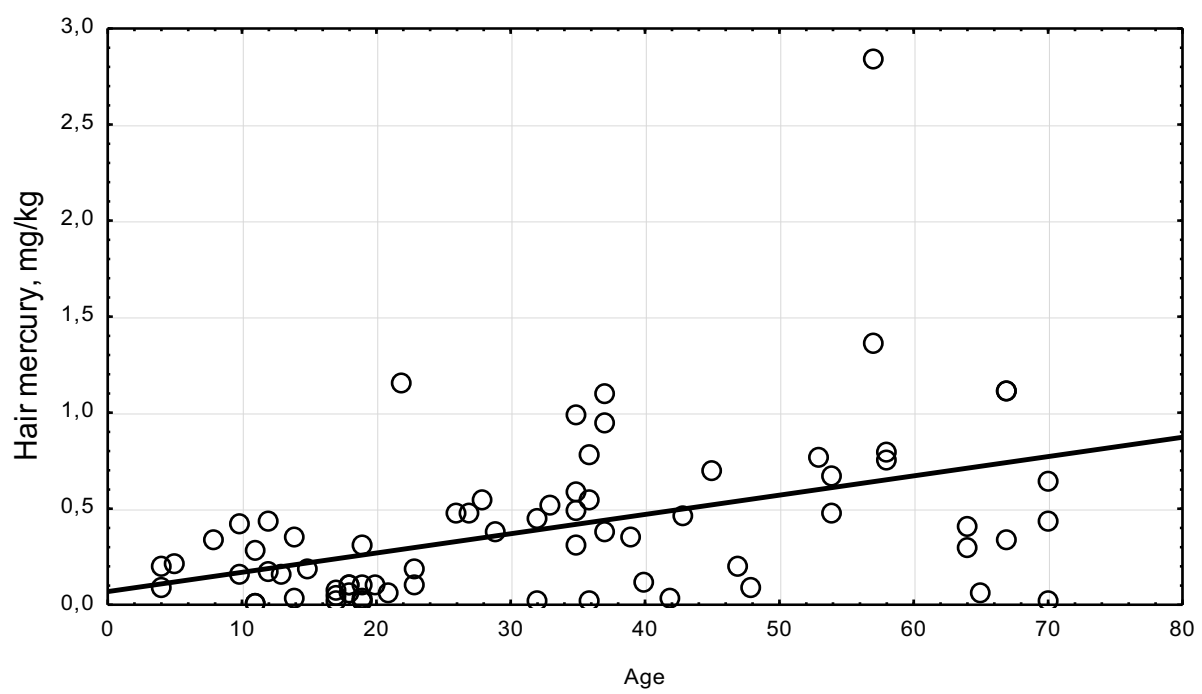

Fig. 2. Correlation of mercury in the hair of the study participants with age

At the same time, a negative correlation was found in a study in Naples, Italy $(r s=$ $0.345(p=0.000))$ [15].

Fish consumption is the main source of mercury intake in the human body [1]. The concentrations of mercury in the hair significantly differ $(p=0.010)$ depending on the consumption of fish by residents of the Babushkinsky district once a month and several times a week (Fig.3, Table 4). The maximum concentrations of mercury were observed in people who consume fish several times a week $(0.538 \pm 0.093 \mathrm{mg} / \mathrm{kg})$. The average mercury content in the hair of people who consume fish less than once a month is $(0.262 \pm$ $0.041 \mathrm{mg} / \mathrm{kg}$ ).

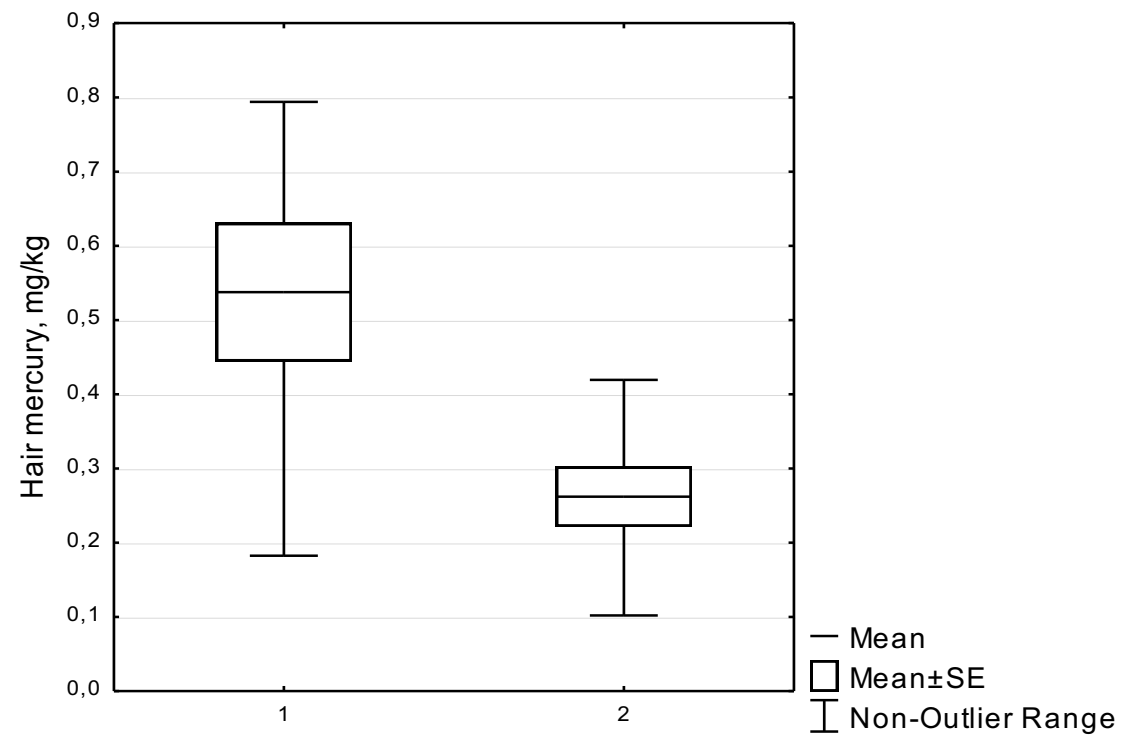

Fig. 3. Concentrations of mercury in the hair of Babushkinsky district residents depending on the frequency of fish consumed (1- $\geq 1$ meal /week, $2-\leq 1$ meal /month) 
Table 4. The indicators of mercury content in human hair depending on the frequency of fish consumption, $\mathrm{mg} / \mathrm{kg}$

\begin{tabular}{|c|c|c|c|c|c|c|c|}
\hline Fish consumption & $\mathrm{N}$ & Mean & Median & Minimum & Maximum & SD & SE \\
\hline$\geq 1$ meal /week & 35 & 0.538 & 0.436 & 0.010 & 2.830 & 0.552 & 0.093 \\
\hline$\leq 1 \mathrm{meal} /$ month & 36 & 0.262 & 0.242 & 0.001 & 1.093 & 0.244 & 0.041 \\
\hline
\end{tabular}

The same differences were observed in the coastal Kirillovsky district, Vologda Region; in Japan in the area of the Karakuwacho Peninsula [9, 17]; in central Poland; in Germany; in studies in the territory of Naples, Italy [13-15].

\section{Conclusion}

In the course of this study, it was found that the average content of mercury in the hair of residents of the Babushkinsky district, Vologda region is $0.398 \pm 0.053 \mathrm{mg} / \mathrm{kg}$. At the same time, it is several times less than the levels of mercury in the hair of the western population of the Vologda Region (Kirillovsky district) [9]. 8\% of the study participants reported exceeding regulatory standards (US EPA). There were no differences in the level of mercury in the hair between men and women. Significantly high concentrations of mercury were observed in the hair of people over 30 years of age. This fact is supported by the established correlation. Depending on the frequency of fish consumption, it was found that significantly the maximum concentrations of mercury were observed in people who consume fish several times a week.

\section{References}

1. UNEP. https://www.who.int/foodsafety/publications/risk-mercury-exposure/en/ (2008)

2. N. Nemova, E. Kaivarainen, M. Krupnova, L. Bondareva, L. Toivonen, V. Komov, Mengen- und spurenelemente, 814-818 (2000)

3. M. Horvat, J. Snoj Tratnik, A. Miklavčič, Biomarkers Hum Biomonitoring 1, 381-417 (2011)

4. P. Grandjean, P.J. Landrigan, Lancet, 368, 2167-2178 (2006)

5. NRC, (2000)

6. V. T. Komov, E. S. Ivanova, V. A. Gremyachikh, N. Y. Poddubnaya, Bull Environ Contam Toxicol 97, 480-485 (2016)

7. L.S. Khabarova and E.S. Ivanova and N.Ya. Poddubnaya and A.V. Andreeva and A.P. Selezneva and D.M. Feneva, Russia Adv. Eng. Res. , 177, 96 - 100 (2018)

8. E. S. Ivanova, V. T. Komov, L. S. Khabarova, Y. G. Udodenko, D. E. Bazhenova, N. Y. Poddubnaya, N. A. Bushmanova, Russia Adv. Eng. Res., 191, 75-79 (2020)

9. O.Y. Rumiantseva, E.S Ivanova, A.S. Elizarova, V.T. Komov, N.Y. Podduobnaia, Russia Adv. Eng. Res., 177, 112-116 (2018)

10. O.Yu. Maximova, E.S. Ivanova, Int. J. Stud. Res., 4, 268-272 (2016)

11. M. Harada, J. Nakanishi, E. Yasoda et al., Environ. Int., 27, 4, 285- 290 (2001)

12. S. Bose-O'Reilly, B. Lettmeier, D. Shoko, G. Roider, G. Drasch, U. Siebert, Environ. Res., 184, 109266 (2020)

13. M. Marcinek-Jacel, J. Albińska, A. Pawlaczyk, M. I. Szynkowska, Environ Toxicol Pharmacol, 55, 196-201 (2017) 
14. G. Schwedler, M. Seiwert, U. Fiddicke, et al., Int J Hyg Envir Heal, 220(4), 686-696 (2017)

15. S. Diez, P. Montuori, A. Pagano, P. Sarnacchiaro, J.M. Bayona, M. Triassi,. Environ. Int., 34, 162-167 (2008)

16. M. Fujimura, A. Matsuyama, J.-P. Harvard, J.-P. Bourdineaud, K. Nakamura, Bull Environ Contam Toxicol, 88 (2), 135-139 (2011)

17. J. Yan, K. Inoue, A. Asakawa, K.H. Harada, T. Watanabe, N. Hachiya, A. Koizumi, Bull Environ Contam Toxicol, 93 (1), 36-41 (2014) 